\title{
DERECHO Y POLÍTICAS AMBIENTALES EN ARAGÓN (PRIMER SEMESTRE 2021) ${ }^{(*)}$
}

\author{
Olga Herrálz Serrano \\ Letrada de las Cortes de Aragón \\ Profesora Asociada Doctora de Derecho Administrativo \\ Universidad de Zaragoza
}

SUMARIO: 1. INTRODUCCIÓN. 2. LEGISLACIÓN: 2.1. Simplificación administrativa. 2.2. Residuos. 2.3. Incendios forestales. 3 ORGANIZACIÓN. 4. GESTIÓN: 4.1. Presupuesto. 2.2. Adaptación de zonas de intervención o vulnerables. 4.3. Gestión de los espacios naturales protegidos. 5. MEDIDAS DE FOMENTO DE CARÁCTER AMBIENTAL.

\section{INTRODUCCIÓN}

Lamentablemente, el final del año 2020 y el comienzo del año 2021 que nos corresponde analizar en estas líneas han seguido marcados por la crisis sanitaria ocasionada por la pandemia del COVID-19 y sus repercusiones en todas las políticas sectoriales, también en la medioambiental. Sin ir más lejos, y en íntima conexión con esta, la reciente Orden SAN/52/2021, de 15 de febrero, se dirige a adoptar determinadas medidas excepcionales en relación con la campaña agrícola 2021 para tratar de evitar los efectos de propagación del virus que tuvo el año anterior. Igualmente, con motivo de la aprobación del presupuesto de la Comunidad Autónoma para este año como se indicará después, se incluyeron partidas con cargo al fondo REACT-EU (Reactiva la Unión Europea), que se ha concebido como un instrumento a corto y a medio plazo para hacer frente a las secuelas socio-económicas de la pandemia,

(*) El presente trabajo se incluye dentro de las actividades del Grupo consolidado de investigación ADESTER (Estudios Territoriales), reconocido por el Gobierno de Aragón (BOA núm. 48, de 20 de abril de 2005). 
también en el área medioambiental. En las líneas que siguen, daremos cuenta de las escasas novedades legislativas y de las principales líneas de actuación seguidas en la materia en el semestre de que damos cuenta.

\section{LEGISLACIÓN}

\subsection{SIMPLIFICACIÓN ADMINISTRATIVA}

La Ley $1 / 2021$, de 11 de febrero, de simplificación administrativa (publicada en BOA 23 febrero) se dicta con la loable intención de impulsar definitivamente las conocidas técnicas del silencio administrativo positivo o la comunicación y la declaración responsable, de reducir plazos de tramitación o documentación exigible, así como de acumular o eliminar trámites, para lo cual se convierte en una suerte de ley paraguas que exigirá una amplia adaptación normativa en la Comunidad a que obliga su disposición final decimosexta. A los efectos de la presente crónica, destacaremos que por medio de sendas disposiciones finales ha llevado a cabo la modificación de varias leyes ambientales. Ia Ley 10/2013, de 19 de diciembre, del Instituto Aragonés de Gestión Ambiental; la Ley 1/2015, de 15 de marzo, de Caza de Aragón; el Decreto Legislativo 1/2017, de 20 de junio, del Gobierno de Aragón, por el que se aprueba el texto refundido de la Ley de Montes de Aragón; y la Ley 10/2005, de 11 de noviembre, de vías pecuarias de Aragón, introduciendo en ellas distintas medidas de simplificación de procedimientos.

\subsection{Residuos}

El Decreto 114/2020, de 25 de noviembre, del Gobierno de Aragón, modificó el Decreto 148/2008, de 22 de julio, por el que se aprueba el Catálogo Aragonés de Residuos, para incorporar la posibilidad de que, con carácter excepcional, sean autorizadas operaciones distintas de las especificadas expresamente por el Catálogo para cada tipo de residuo siempre y cuando estas operaciones de tratamiento presenten mayor beneficio ambiental, justificando las mejoras aportadas. Entre estas, se consideran una reducción de 
la cantidad final de residuos resultantes, de su peligrosidad, de las emisiones, o de la contaminación de cualquier naturaleza, una reducción del consumo energético, o la puesta en marcha de tecnologías innovadoras. Lo dispuesto en el artículo único del Decreto 114/2020 deberá ser tenido en cuenta especialmente en la tramitación del procedimiento para la concesión de autorizaciones ambientales integradas.

\subsection{INCENDIOS FORESTALES}

En el último tramo del ejercicio 2020 que también es objeto de esta Crónica, se aprobó (mediante Orden AGM/1044/2020, de 9 de octubre, BOA 4 noviembre) una modificación de los límites de las Zonas de Intervención definidas en el anexo V del Decreto 167/2018, de 9 de octubre, del Gobierno de Aragón, por el que se aprueba el Plan Especial de Protección Civil de Emergencias por Incendios Forestales (PROCINFO), para ajustarlas a áreas medioambientales completas.

\section{ORGANIZACIÓN}

En este apartado, lo único reseñable es la Resolución de 28 de enero de 2021, del Presidente del Instituto Aragonés del Agua, por la que se llevó a cabo la renovación de los vocales de entidades representativas de usos turísticos, recreativos, acuícolas y otros, en el seno de la Comisión del Agua de Aragón (BOA 17 febrero), en concreto mediante el nombramiento de los representantes titulares y suplentes propuestos por la Federación Aragonesa de Pesca y Cásting, y la Asociación de Empresas de Turismo Deportivo de Aragón.

\section{GESTIÓN}

\subsection{Presupuesto}


Tras la aprobación de la Ley 4/2020, de 30 de diciembre, de Presupuestos de la Comunidad Autónoma de Aragón para el ejercicio 2021 (BOA 31 diciembre), el presupuesto consolidado del Departamento de Agricultura, Ganadería y Medio Ambiente (incluyendo, por tanto, al Instituto Aragonés del Agua y al Instituto Aragonés de Gestión Ambiental como entidades de derecho público dependientes) ascenderá a 815,08 millones de euros, lo que representa un incremento de veinte millones con respecto al aprobado en 2020. A ellos habría que sumar los diez millones consignados en la sección treinta del presupuesto ("Varios departamentos") con cargo al nuevo fondo REACT-EU (Reactiva la Unión Europea), que se concibe como un instrumento a corto y a medio plazo para hacer frente a las secuelas socioeconómicas de la pandemia. Se trata del presupuesto más elevado del departamento desde el 2013. De los treinta millones de euros de aumento, quince son de fondos propios, procediendo el resto del Gobierno de España y de fondos europeos extraordinarios.

Por lo que respecta a la parte medioambiental del departamento, el incremento de las partidas presupuestarias se cifra en 7,6 millones de euros. Entrando en el análisis de las mismas, el presupuesto de la Dirección General de Calidad y Seguridad Alimentaria es de 16,3 millones de euros, que deberán dedicarse a ejecutar el Programa 7161, del mismo nombre, entre cuyos objetivos para el ejercicio 2021 se encuentran las actividades de planificación, coordinación, conservación y supervisión de la gestión de los recursos cinegéticos y piscícolas, la elaboración de los planes autonómicos de caza y pesca y la planificación y gestión de las piscifactorías propiedad del Gobierno de Aragón. Asimismo, en el mencionado Programa, se integran competencias relativas al control ambiental.

Por lo que respecta a la Dirección General de Cambio Climático y Educación Ambiental, gestionará el Programa de Protección y Mejora del Medio Ambiente, que mantiene su presupuesto del ejercicio 2020 de 13,7 millones de euros. Con el mismo, deberán financiarse, entre otras, las actuaciones enmarcadas en el Plan de Gestión Integral de Residuos de Aragón 2018-2022 o el desarrollo y la dinamización de la Estrategia Aragonesa de Educación 
Ambiental (EÁREA) 2030 y de la Estrategia Aragonesa de Cambio Climático Horizonte 2030.

La Dirección General de Medio Natural y Gestión Forestal tiene un presupuesto global de 53,1 millones de euros (mejorando los 49,3 del ejercicio anterior) de los que 38,6 corresponden al Programa de Protección y Mejora del Medio Natural y 14,4, al Programa para la Conservación de la Biodiversidad y Desarrollo Sostenible.

Pasando a la consideración del presupuesto de las entidades de derecho público adscritas al departamento y de las sociedades públicas autonómicas que persiguen objetivos ambientales, comenzaremos por el Instituto Aragonés de Gestión Ambiental, que va a contar durante 2021 con un presupuesto ligeramente superior al del ejercicio anterior, elevándose hasta los 5.849.163 euros frente a los 5.549.163 de 2020.

En cuanto al Instituto Aragonés del Agua, ve incrementado el suyo para 2021 en un 5,11\% ascendiendo a casi setenta y ocho millones de euros para la ejecución del Programa de gestión e infraestructura de recursos hidráulicos. Para el ejercicio 2021, la principal fuente de financiación del IAA seguirá siendo la recaudación del Impuesto sobre la Contaminación de las Aguas, habiéndose efectuado una previsión de sesenta y nueve millones de euros de recaudación por este concepto, tres más que en el ejercicio anterior.

En cuanto a las sociedades públicas ambientales, la Sociedad Aragonesa de Gestión Agroambiental, S.L.U. (SARGA) contará en 2021 con un presupuesto total de 53.579.106 euros, lo que representa un incremento en millón y medio con respecto al ejercicio 2020. Por su parte, para la Sociedad Aragonesa de Gestión de Residuos, S.A. (ARAGERSA), se ha previsto para 2021 un presupuesto de explotación inferior en algo más de cien mil euros respecto al de 2020, alcanzando 1.727 .681 euros.

Una breve referencia merece la partida consignada para el Consorcio Reserva de la Biosfera Ordesa-Viñamala, surgido de un Convenio de colaboración entre el Organismo Autónomo Parques Nacionales, el Gobierno de Aragón y los Ayuntamientos de Bielsa, Biescas, Broto, Hoz de Jaca, 
Panticosa, Puértolas, Sallent de Gállego, Tella-Sin, Torla y Yésero. Para el año 2021, el ejecutivo autonómico dedicará 53.313 euros para el funcionamiento del consorcio.

Por último, el Anexo VII de los presupuestos desglosan las cantidades que la Comunidad Autónoma destina a la financiación de cada uno de los Objetivos de Desarrollo Sostenible, siendo las siguientes las cuantías que, en el año 2021, se consignan para los que tienen que ver con la protección medioambiental. Así, al objetivo 6 (Agua limpia y saneamiento) se destinarán 73,4 millones de euros (frente a los 70,2 de 2020). Al objetivo 13 (Acción por el clima), 11,2 millones por 11,6 en el ejercicio anterior. $Y$ al objetivo 15 (Vida de ecosistemas terrestres), 49,2 millones, lo que significa casi 5 más que en 2020 $(44,4)$.

\subsection{ADAPTACIÓN DE ZONAS DE INTERVENCIÓN O VULNERABLES}

La Orden AGM/1044/2020, de 9 de octubre, por la que se adaptan al marco territorial de las Áreas Medioambientales las Zonas de Intervención definidas en el anexo V del Decreto 167/2018, de 9 de octubre, del Gobierno de Aragón, por el que se aprueba el Plan Especial de Protección Civil de Emergencias por Incendios Forestales (BOA 4 noviembre), se dirige básicamente a corregir errores tanto en la denominación como en la delimitación de algunas Zonas de Intervención Forestal para hacerlas coincidentes con áreas medioambientales de cara a facilitar la gestión en casos de emergencia por incendios forestales.

En otro orden de cosas, pero en este caso para las actuaciones preventivas en materia de contaminación de las aguas, se aprobó la Orden AGM/83/2021, de 15 de febrero, por la que se designan y modifican las Zonas Vulnerables a la contaminación de las aguas por nitratos procedentes de fuentes agrarias en la Comunidad Autónoma de Aragón y por la que se aprueba el $\vee$ Programa de Actuación sobre las Zonas Vulnerables de Aragón (BOA 4 marzo). 
La Directiva 91/676/CEE del Consejo, de 12 de diciembre de 1991, relativa a la protección de las aguas contra la contaminación producida por nitratos utilizados en la agricultura, impuso a los Estados miembros la obligación de identificar dichas aguas, y estableció los criterios para designar como "Zonas Vulnerables" aquellas superficies territoriales cuyo drenaje da lugar a la contaminación por nitratos. Traspuesta a nuestro ordenamiento por el Real Decreto 261/1996, de 16 de febrero, este estableció la obligación de revisar, al menos cada cuatro años, los Programas de Actuación sobre las Zonas Vulnerables designadas con el fin de modificarlos o adaptarlos, si fuera necesario.

En Aragón, la Orden DRS/882/2019, de 8 de julio, designó y modificó las Zonas Vulnerables, datando de 2013 el IV Programa de Actuación sobre ellas aprobado por la Comunidad Autónoma. Habiendo solicitado, no obstante, la Comisión Europea la declaración urgente de nuevas zonas vulnerables en España por parecer insuficiente el territorio declarado hasta ahora para los niveles de nitratos detectados en las estaciones de control por las distintas confederaciones hidrográficas, el departamento con competencias en materia de medio ambiente del Gobierno de Aragón ha optado por ampliarlas, objeto al que se dirige la Orden AGM/83/2021. Se anexa a la misma el V Plan de Actuación sobre las Zonas Vulnerables de la Comunidad con un amplio elenco de medidas a aplicar en función de los terrenos y cultivos.

\subsection{Gestión de LOS eSPacios natURALES PROtegidos}

Los glaciares del Pirineo fueron declarados Monumentos Naturales por la Ley 2/1990, de 21 de marzo. Conforme a la legislación entonces vigente, por Decreto 271/2002, se aprobó el correspondiente Plan de Protección como instrumento de gestión de aquellos, pero, una vez finalizado su plazo de vigencia, había que sustituirlo por un Plan Rector de Uso y Gestión conforme a las nuevas exigencias del texto refundido de la Ley de Espacios Protegidos de Aragón. Surge así el Decreto 104/2020, de 28 de octubre, del Gobierno de Aragón, por el que se aprueba el Plan Rector de Uso y Gestión de los 
Monumentos Naturales de los Glaciares Pirenaicos. Como es propio de este tipo de instrumentos, contempla la zonificación de su ámbito geográfico y de su Zona Periférica de Protección; los objetivos específicos de conservación a alcanzar durante su vigencia; la casuística de usos prohibidos y compatibles; las directrices orientadoras de las actuaciones que puedan llevarse a cabo en su ámbito territorial por sectores económicos; y el programa de acciones que se proyecta llevar a cabo a diez años vista. No obstante, el Plan Rector de Uso y Gestión podrá modificarse antes del fin de su período de vigencia si se dieran circunstancias que aconsejasen su revisión o se produjeran variaciones sustanciales en la realidad física del espacio natural.

También en este apartado relativo a la gestión de los espacios naturales protegidos, debemos dar cuenta de la aprobación del Decreto 13/2021, de 25 de enero, del Gobierno de Aragón, por el que se declaran como Zonas de Especial Conservación los 156 espacios que fueron designados Lugares de Importancia Comunitaria en la Comunidad Autónoma de Aragón por las Decisiones de Ejecución (UE) 2020/96 y 2020/100, de la Comisión, ambas de 28 de noviembre. El citado Decreto aprueba también por fin los planes de gestión de dichas Zonas de Especial Conservación, así como los planes de gestión de las Zonas de Especial Protección para las Aves de la Red Natura 2000 en Aragón, dando cumplimiento así a las cartas de emplazamiento que se habían recibido de las instituciones comunitarias dado el retraso de años.

Precisamente, porque han sido 407 los planes de gestión aprobados, que suman más de un millón trescientas mil hectáreas afectadas, el Decreto hubo de ser completado mediante diversas Resoluciones del Director General de Medio Natural y Gestión Forestal para dar publicidad a todos ellos (las mismas han sido publicadas en BOA 6 febrero, 19 febrero, 20 febrero, 26 febrero, 27 febrero, 5 marzo, 6 marzo, 12 marzo, 13 marzo, 19 marzo, 26 marzo, 27 marzo, 3 abril, 9 abril, 10 abril). Se atribuye a dichos planes una vigencia de seis años, si bien deberán ser evaluados en una fase intermedia, con base en el mejor conocimiento científico y técnico de ese momento, de cara a revisarlos en su caso. 


\section{MEDIDAS DE FOMENTO DE CARÁCTER AMBIENTAL}

Meramente, a título informativo de la política de fomento en materia medio ambiental seguida por la Administración de la Comunidad Autónoma durante los meses que analizamos, se convocaron las siguientes subvenciones: las LEADER para gastos de explotación y animación de los grupos de acción local para el ejercicio 2021 (Orden AGM/1279/2020, de 30 de noviembre, BOA 17 diciembre); con cargo al Fondo de Inversiones de Teruel 2020 dirigida a entidades locales para impulsar actuaciones relativas a la redacción de proyectos de mejora de la depuración de aguas residuales en la provincia de Teruel (Orden AGM/171/2021, de 3 de marzo, BOA 18 marzo), así como subvenciones destinadas a apoyar la nueva participación en regímenes de calidad, para el año 2021 (Orden AGM/295/2021, de 22 de marzo, BOA 7 abril).

También por Orden AGM/66/2021, de 10 de febrero, se establecieron las bases reguladoras para la concesión de subvenciones para el transporte y la aplicación de estiércoles por los centros gestores de estiércoles de la Comunidad Autónoma de Aragón (BOA 1 marzo).

Asimismo por Orden AGM/270/2021, de 17 de marzo (BOA 5 abril), se convocó el Premio Aragón Medio Ambiente para el año 2021. 